\title{
Studying reaction time with nonaging intervals: An effective procedure
}

\author{
ROBERT GOTTSDANKER, TIM PERKINS, and JAHAN AFTAB \\ University of California, Santa Barbara, California
}

\begin{abstract}
The nonaging-intervals procedure, in which momentary probability of stimulus occurrence remains constant, is preferable in principle to varied or constant intervals for double-stimulation experiments on reaction time (RT). However, elevation of RT has uniformly been found at short waiting intervals on single-stimulation baseline tasks. Effects attributable to the first stimulus on double-stimulation tasks would thus be confounded. The required level baselines were obtained for both simple and choice reactions by combining the transit-signal method with nonaging intervals. Possible reasons for this success were the elimination of timekeeping error and psychological refractoriness. Results with precued full response information show the expected decline of RT with increase of precue-to-stimulus interval. Suggestions are given for the use of nonaging intervals for studying the attentional demands of movements and the influence of level of momentary probability on basic RT effects.
\end{abstract}

In the nonaging-intervals procedure for studying reaction time (RT) devised by Nickerson (1967), the imperative stimulus, $S$, for response cannot occur on a trial before a designated moment, time zero, and then maintains a fixed momentary probability of occurring. At time zero or at any subsequent evenly spaced moment, it is made equally probable that $S$ will occur if it has not yet occurred on the trial, the Bernoulli process. When the interval between moments is infinitesimal, the following exponential probability density is obtained: $(1 / W) \mathrm{e}^{-T / W}$, where $W$ is the mean waiting interval and $T$ is time since time zero. This version of nonaging intervals was used in the present study.

If the only stimulus presented on a trial (aside from a ready signal) is the imperative stimulus, $S$, the interval between time zero and $S$ may be called the waiting interval (WI). If the method is extended to examine the time course of beneficial or detrimental effects on RT of a stimulus, $P$, which occurs at time zero, the interval between $P$ and $S$ would then be the interstimulus, or intersignal, interval (ISI). If $\boldsymbol{P}$ is a precue that gives advance response information (Gottsdanker \& Shragg, 1985), a beneficial effect on RT may be expected. In the paradigm for studying the psychological refractory period (PRP), a detrimental effect is expected from the presentation of $P$, which typically requires its own response (Welford, 1952). The critical datum in either kind of doublestimulation experiment is the relation between RT and ISI. With lengthening ISI, beneficial effects of $P$ are expected to increase, to a point, and detrimental effects to diminish. A precise assessment of the slope is required. The

This research was supported by Grant No. MH39359 to the University of California from the National Institute of Mental Health. Requests for reprints should be sent to R. Gottsdanker, Department of Psychology, University of California, Santa Barbara, CA 93106. subtraction method of Donders (1868/1969) demands that an initial -1 slope be found when full response information is precued (Gottsdanker \& Shragg, 1985). A -1 slope is also demanded by the single-channel hypothesis of PRP (Welford, 1952).

\section{THE PREFERABILITY, IN PRINCIPLE, OF NONAGING INTERVALS FOR DOUBLE-STIMULATION EXPERIMENTS}

It seems clear that nonaging intervals are preferable to varying intervals for studying the time course of the effect of $P$ in double-stimulation tasks. In the variedintervals procedure, there is an upper limit to the range of moments at which $S$ can occur. If no catch trials are used, the momentary probability of $S$ increases to unity at the end of the range (Nickerson, 1967). Thus, on a double-stimulation task, the relation between ISI and RT is confounded with change in momentary probability. This latter variable has been found to be a powerful influence on RT in single-stimulation studies (Drazin, 1961; Gottsdanker, 1970b). If catch trials are employed, the situation is changed but not remedied. First, the momentary probability of $S$ still increases over the range, even though it does not reach unity. Contrariwise, the probability that $S$ will occur at all on the trial steadily declines. Use of catch trials has, in fact, been accompanied by a rise in $\mathrm{RT}$ at the longest intervals, in both single-stimulation experiments and the PRP procedure (Davis, 1956; Drazin, 1961; Gottsdanker, 1980). In addition, the use of nonaging intervals is also preferable to having trials blocked at constant ISIs. In that procedure, there is the danger that the subject's mental set will be different on blocks of trials having short or long ISIs. For example, in an experiment on PRP, the subject may put forth greater effort on trials with short ISIs than in the less-demanding situation of long ISIs. While it cannot be proved that such effects occur 
with constant ISIs, there is no way of guarding against the possibility. ${ }^{1}$

\section{THE PROBLEMS, IN PRACTICE, IN USE OF NONAGING INTERVALS}

In the critique of the varied-intervals procedure in the previous section, it was tacitly assumed that since momentary probability remains constant with nonaging intervals, average RT will likewise remain constant in the absence of the influence of a preceding stimulus. It is known that this cannot be entirely true. On single-stimulation tasks with high momentary probability, RT begins to rise after WIs that are longer than $1 \mathrm{sec}$ are reached. This effect, found for both simple and choice RT, has been variously ascribed to central fatigue (Gottsdanker, 1984; Näätänen, 1971), conflict between facilitatory and inhibitory motor processes (Näätänen, 1971), and unwillingness to maintain a high level of preparation (Gottsdanker, 1975). Still, the effect is not serious for most double-stimulation experiments in which the ISIs of interest are considerably shorter, seldom over $500 \mathrm{msec}$. However, far more serious is the uniform finding in single-stimulation experiments, with epoch lengths of $250 \mathrm{msec}$ or less between moments, that RT is elevated at the shortest WIs. Examples are shown in Figure 1 of this effect, which may be termed short-interval elevation, for a small group of sub- jects on simple RT (Nickerson, 1967) and for a single subject on choice RT (Green, Smith, \& von Gierke, 1983). In the instances shown, the mean WI was $1 \mathrm{sec}$. However, the same finding has been obtained over a wide range of mean WIs (Nickerson \& Burnham, 1969). If the elevation cannot be eliminated, the effect of $P$ on RT as a function of ISI is not interpretable. In order to eliminate shortinterval elevation, it would be useful to understand its causes.

Some leads are provided by the differences between the Nickerson (1967) and Nickerson and Burnham (1969) procedures, on the one hand, where the elevation was sometimes over $100 \mathrm{msec}$, and the procedures of Green et al. (1983), where the elevation did not exceed $30 \mathrm{msec}$. One obvious difference is that a choice reaction was used by Green et al., whereas the other investigators used a simple reaction. Unfortunately, this information does not help in devising a procedure to eliminate the effect, as simple-RT baseline as well as choice-RT baselines are needed in many double-stimulation experiments. Another difference is in the possibility of PRP interference from the presentation of the warning signal. Green et al. used a countdown method, with the last 100 -msec stimulus ending at time zero, whereas the other investigators used a ready signal that came on at time zero. Nickerson (1967), in fact, considered his procedure as a test of PRP. Nickerson and Burnham (1969), using the same procedure,

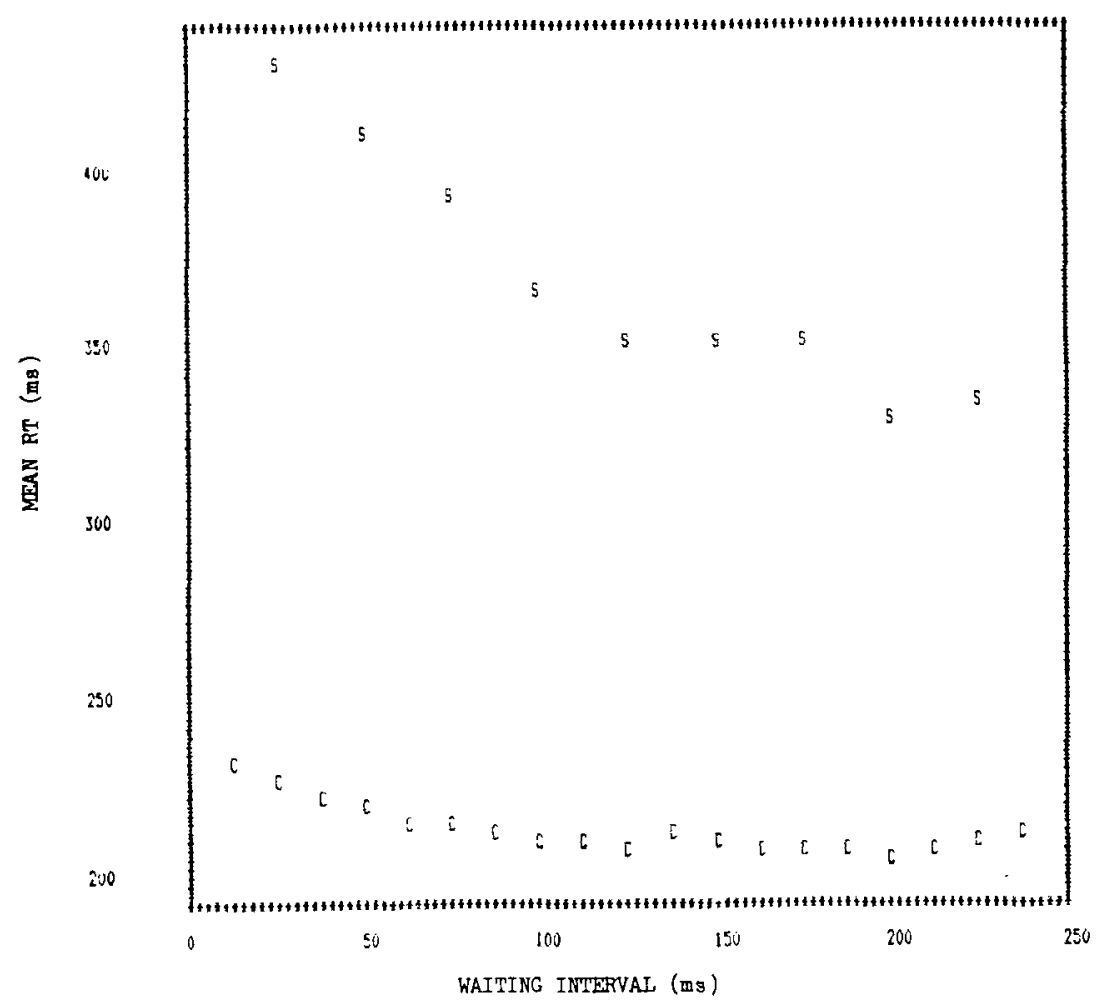

Figure 1. Relation found between waiting duration and RT in two previous investigations. Simple RT (indicated by ssss) was obtained in the study by Nickerson (1967), and choice RT (indicated by ccec) in the study by Green et al. (1983). Mean WI was $1 \mathrm{sec}$ in both studies. RTs are plotted to the nearest 2.5 msec. 
only suggested that short-interval elevation is related to the PRP, and switched to the use of the term foreperiod rather than intersignal interval. Green et al. do not attempt to explain the phenomenon; they merely acknowledge the effect and refer to the similar finding obtained by Nickerson and Burnham. To the extent that something like PRP is involved, it would be expected that the effect would be diminished by the cushion in the procedure of Green et al., where time zero occurred $100 \mathrm{msec}$ after the onset of the last countdown stimulus. Thus, it appears a good idea to avoid use of warning signals near time zero, if possible. However, the major factor in the difference might be the much better timekeeping afforded by the countdown procedure of Green et al. In Nickerson's and Nickerson and Burnham's studies, time zero occurred $3 \mathrm{sec}$ following the previous response. It appears, in this case, that subjects were not yet prepared at time zero and shortly afterward because they were unsure of when the "zone"' would start. The anomaly that their simple RTs were much longer than the choice RTs of Green et al. may be due, in part, to the timekeeping difference. This is quite different from the situation of varied intervals where short-interval elevation is increased by improved timekeeping (Gottsdanker, 1970b). However, the cases are similar in that the expected effects of a changing or a fixed momentary probability are realized when timekeeping error is minimized. It might be noted that Green et al. used nonaging intervals as a guard against anticipatory responses, as dictated by the problem they were investigating. In further pursuing this goal, they imposed a heavy penalty for anticipations. This might have made subjects timid in respect to their level of response preparation around time zero.

\section{A METHOD TO OVERCOME ELEVATION OF RT AT BRIEF WIs}

From the foregoing analysis, it seems possible that short-term elevation might be eliminated through use of the transit-signal method (Gottsdanker, 1970a) in conjunction with nonaging intervals. Such a combination has, in fact, already been employed in studies of the maintaining of preparation (Gottsdanker, 1975, 1984), but with epoch lengths of 400 and 500 msec between moments, so the issue of present interest was not addressed. The epoch length for the studies by Nickerson (1967) and by Nickerson and Burnham (1969) was $25 \mathrm{msec}$, whereas for Green et al. (1983), the stimulus could occur at any instant. In the transit-signal method, the subject sees a target move at a constant rate toward a reference line. A stimulus cannot be given until the target reaches this line. Thus, timekeeping error is virtually eliminated. Moreover, as no sudden-onset warning signal need be employed to announce time zero, the danger of psychological refractoriness should also be reduced. This approach was tested and found to be successful in eliminating shortterm elevation. In the procedure that evolved, a target bar ascends the RT display over a period of $3 \mathrm{sec}$ until it reaches a gap in a horizontal reference line. Time zero, the first possible moment of occurrence of the imperative tone stimulus, $S$, is $200 \mathrm{msec}$ after this instant. This cushion, similar to that provided by Green et al., seems necessary to prevent interference from previous attention to the moving target bar. The instantaneous probability of stimulus occurrence at or after time zero was held constant at $.001 /$ millisecond, thus providing a mean WI of $1 \mathrm{sec}$, as was the case for the data shown in Figure 1. A convenient method for generating nonaging intervals is presented in the Appendix. For a choice reaction in the task studied, the tone was accompanied by the brightening of a side bar, either to the right or left of center. The response was a forward leverpress, with either the right or left hand, according to the side of stimulation. For a simple reaction, the side bar brightened at the beginning of motion of the target bar, with the already selected respose's being made to the occurrence of the tone. These particular versions of choice and simple reactions were used in order to provide the appropriate baseline conditions for comparison with reaction for which full-response information was precued. In the precued condition, the left or right side bar brightened at time zero, with the response made to the tone, whenever it occurred. The arrangements for simple, choice, and precued reactions are shown in Figure 2. Mean WI (or ISI for the precued condition) was $1 \mathrm{sec}$, as is the case for the data shown in Figure 1. Four young adults were tested, with 900 trials given on each condition.

\section{FINDINGS WITH THE TRANSIT-SIGNAL PROCEDURE}

In Table 1, the mean RTs on correct responses and associated standard deviations (SDs) are presented for each subject for three ranges of WI or ISI: $0-75 \mathrm{msec}, 76-158$ msec, and $159-250 \mathrm{msec}$. There were 66 reactions for a subject within any range for a given condition. No more than $6 \%$ of trials for any combination of subject and condition had errors or malfunction of the equipment. Also shown is the outcome of the one-way ANOVAs. Precued reactions showed significant variation at the .001 level for all 4 subjects. Contrariwise, there was no statistically significant value of $F$ for simple or choice reaction for any subject. Still, it may be observed that uniformly horizontal functions were found for Subjects 1 and 2 only. Subject 4 shows some indication of short-interval elevation on choice reactions, and Subject 3 on both simple and choice reactions.

With the present procedure, subjects can be found with sufficiently flat baselines to allow testing the slope of RT against ISI. This has not been the case previously. Beyond that, it seems quite possible that most subjects may be brought up to this standard either by providing them with extensive practice or by further development of the procedure. The slow reactions of Subjects 3 and 4 as compared with those of Subjects 1 and 2, and the extremely high variability of Subject 3 strongly suggests that Sub- 


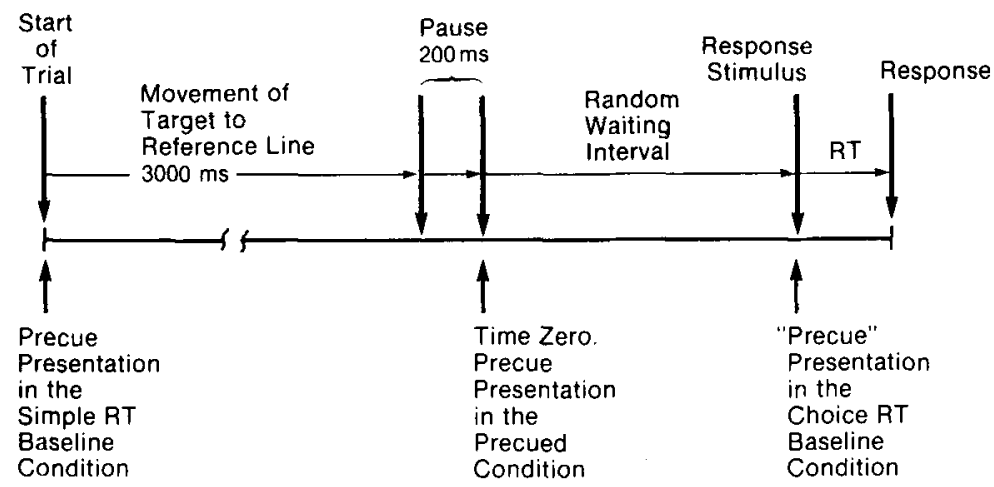

Figure 2. Arrangements for obtaining simple, choice, and precued RT in the method of nonaging intervals that incorporates use of the transit-signal technique.

jects 3 and 4 could benefit from practice. Preliminary work indicated that a mean WI shorter than $1 \mathrm{sec}$ and an interval slightly longer than $200 \mathrm{msec}$ between the end of target motion and time zero might be even more conducive to horizontal baselines.

In any event, the present results are more than encouraging, as can be seen in Figure 3. These continuous functions are based on the reactions of Subjects 1,2, and 4 . Subject 3 was eliminated from this analysis because his excessive variability produced large meaningless "bumps" in the functions. The data utilized are for WIs (or ISIs) up to $250 \mathrm{msec}$ and include 198 trials. These were divided into 22 WI groups of 9 trials (excluding errors) for each subject, and the median was found for each group. The means over the 3 subjects were then smoothed by use of a moving cosine window, the procedure used by Green et al. (1983). It is apparent that there was no elevation of RT at the short WIs on either simple or choice reactions, unlike the examples shown in Figure 1. A com- prehensive study is under way in the present investigators' laboratory to make a definitive test of an initial -1 slope on precued reactions, which would support Donders's subtraction method (Gottsdanker \& Shragg, 1985). The possibility is being investigated that this result will occur only over some limited range of values of mean ISI.

\section{NONAGING INTERVALS IN STUDYING THE ATTENTIONAL DEMANDS OF MOVEMENT}

The procedures that have been described appear adequate for those double-stimulation experiments concerned with PRP or the utilization of advance response information. They may also be applied to studies of the attentional demands of simple movements (Posner \& Keele, 1969). In such studies, a probe stimulus is given at different points along a movement that is being made with one hand to a target or to a stop. The response to the probe is made with the other hand. The RT of the response to the probe

Table 1

Mean Reaction Times, Standard Deviations, and $F$ tests

\begin{tabular}{|c|c|c|c|c|c|c|c|c|}
\hline \multirow[b]{3}{*}{ Condition } & \multicolumn{6}{|c|}{ WI or ISI Range } & \multirow[b]{3}{*}{$F^{*}$} & \multirow[b]{3}{*}{$p$} \\
\hline & \multicolumn{2}{|c|}{$0-75 \mathrm{msec}$} & \multicolumn{2}{|c|}{ 76-158 msec } & \multicolumn{2}{|c|}{$159-250 \mathrm{msec}$} & & \\
\hline & Mean & $S D$ & Mean & $S D$ & Mean & $S D$ & & \\
\hline \multicolumn{9}{|c|}{ Subject 1} \\
\hline Simple & 169 & 27 & 170 & 29 & 166 & 27 & 0.37 & n.s. \\
\hline Choice & 279 & 73 & 270 & 64 & 283 & 65 & 0.59 & n.s. \\
\hline Precued & 244 & 79 & 192 & 57 & 175 & 48 & 68.23 & $<.001$ \\
\hline \multicolumn{9}{|c|}{ Subject 2} \\
\hline Simple & 154 & 17 & 160 & 28 & 158 & 30 & 0.68 & n.s. \\
\hline Choice & 249 & 54 & 246 & 44 & 245 & 43 & 0.14 & n.s. \\
\hline Precued & 200 & 28 & 164 & 21 & 160 & 23 & 53.07 & $<.001$ \\
\hline \multicolumn{9}{|c|}{ Subject 3} \\
\hline Simple & 231 & 64 & 231 & 73 & 218 & 57 & 0.86 & n.s. \\
\hline Choice & 357 & 150 & 346 & 109 & 321 & 94 & 1.38 & n.s. \\
\hline Precued & 344 & 130 & 299 & 129 & 250 & 122 & 8.82 & $<.001$ \\
\hline \multicolumn{9}{|c|}{ Subject 4} \\
\hline Simple & 205 & 33 & 195 & 29 & 195 & 60 & 1.15 & n.s. \\
\hline Choice & 341 & 63 & 327 & 54 & 325 & 67 & 1.15 & n.s. \\
\hline Precued & 311 & 65 & 287 & 79 & 243 & 36 & 22.54 & $<.001$ \\
\hline
\end{tabular}

* $d f=2$ in the numerator and between 168 and 195 in the denominator, depending on the number of trials without error. 


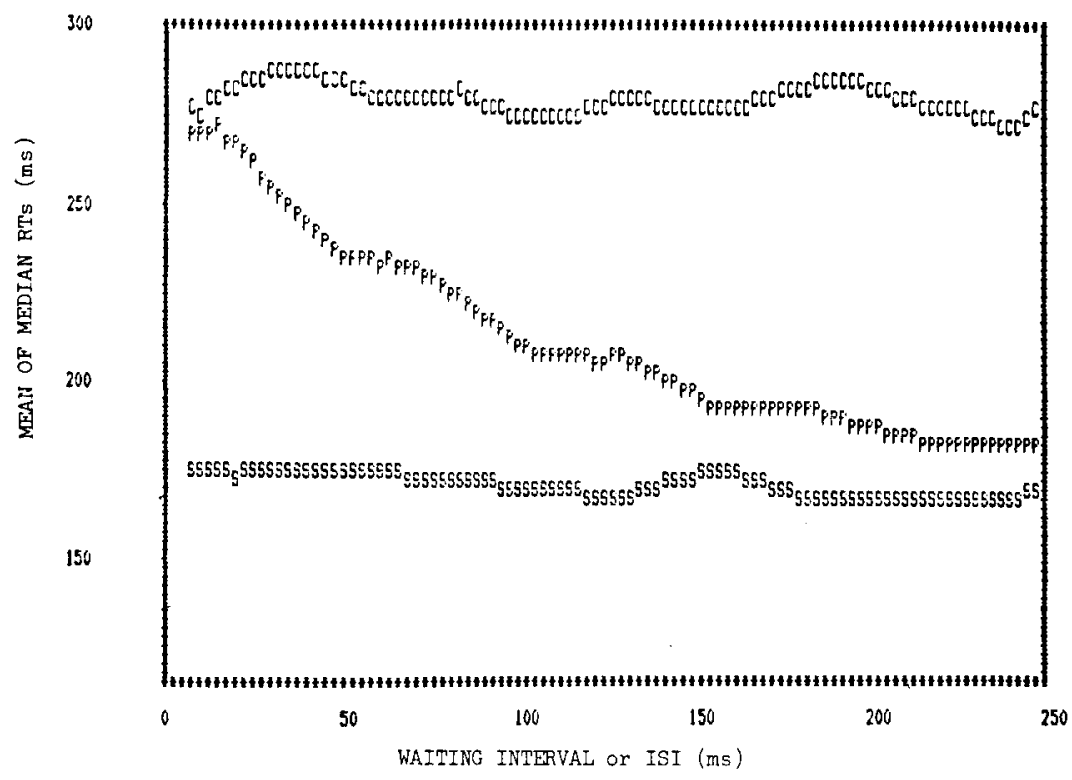

Figure 3. Mean of median RTs for 3 subjects with the method of nonaging intervals that incorporates use of the transit-signal technique. Simple (ssss), choice (cccc), and precued (pppp) RTs were obtained by the arrangement shown in Figure 2. Mean WI (or ISI) was 1 sec. RTs are plotted to the nearest 2.5 msec.

is studied in relation to the point during the movement that the probe is presented. Catch trials are typically used in an attempt to minimize increasing positional probability of probe occurrence. Salmoni, Sullivan, and Starkes (1976) recommended that all such experiments use onethird catch trials. However, whether or not catch trials are used, the varied-position procedure, as it might be called here, is subject to the same problems previously discussed for varied intervals. For example, when catch trials are used, the longer RTs found near the end of the movement might simply reflect the increasing probability that there will be no probe on the trial. Here again, nonaging intervals might be the solution. Let us suppose that time zero is made to coincide with the beginning of the movement. A probe stimulus would occur at that instant or at any other instant during the movement. It is also true that some probe stimuli would occur after the end of the movement. However, this does not seem objectionable. If movement time were recorded on every trial, WI could be translated into percent of this time. The most refined identification of probe position along the motion would require that a continuous record be made of the time course of the movement. To be sure, there still remains the problem, raised by McLeod (1978), of the temporal alignment of movement processing and proberesponse processing.

\section{A MORE GENERAL USEFULNESS OF NONAGING INTERVALS}

Although the present investigation was directed toward double-stimulation tasks, an effective procedure for use of nonaging intervals would provide benefits for the study of RT in general. First, the work of Nickerson and Burnham (1969) on the effect of momentary probability (mean WI) on RT could be followed up, but without the complication of short-interval elevation. Variation of mean WI provides the cleanest approach to the effect of time uncertainty, a problem investigated by Drazin (1961), Karlin (1959), and Klemmer (1956, 1957). Second, the effect of mean WI could be studied in relation to many fundamental functions, including Hick's (1952) law concerning number of alternatives, Hyman's (1953) addition to the law concerning relative probability of alternatives, and stimulus-response compatibility (Fitts \& Seeger, 1953). There are no data at present which indicate whether these relations generalize over mean WI. Finally, it should be noted that experiments in which stimuli have higher or lower momentary probability are far more descriptive of the real world in which responses are made than are experiments in which stimuli are restricted to one instant or to a limited range of instants in time. Thus, they may be said to have greater ecological validity.

\section{REFERENCES}

DAvis, R. (1956). The limits of the "psychological refractory period." Quarterly Journal of Experimental Psychology, 8, 24-36.

DonDERS, F. C. (1969). Over de snelheid van psychische processen [On the speed of psychological processes] (W. Koster, Trans.). In W. Koster (Ed.), Attention and performance, II. Amsterdam: North Holland. (Original work published 1868)

DraziN, D. H. (1961). Effects of foreperiod, foreperiod variability, and probability of stimulus occurrence on simple reaction time. Joumal of Experimental Psychology, 62, 43-50.

FITTS, P. M., \& SEEGER, C. M. (1953). S-R compatibility: Spatial characteristics of stimulus and response codes. Joumal of Experimental Psychology, 46, 199-210. 
GotTSDANKER, R. (1970a). A transit-signal methodology for studying reaction time. Behavior Research Methods \& Instrumentation, 2, 6-8.

GOTTSDANKER, R. (1970b). Uncertainty, timekeeping and simple reaction time. Journal of Motor Behavior, 2, 245-260.

GOTTSDANKER, R. (1975). The attaining and maintaining of preparation. In P. Rabbitt \& S. Dornic (Eds.), Attention and Performance $V$ (pp. 33-49) New York: Academic Press.

GotTsDanker, R. (1980). The ubiquitous role of preparation. In G. E. Stelmach \& J. Requin (Eds.), Tutorials in Motor Behavior (pp. 355 371). Amsterdam: North Holland.

GotTsdanker, R. (1984). Effort of preparation and age. Perceptual \& Motor Skills, 59, 527-538.

GotTsdanker, R., \&HRagG, G. P. (1985). Verification of Donders' subtraction method. Journal of Experimental Psychology: Human Perception \& Performance, 11, 765-776.

Green, D. M., Smith, A. F., \& von Gierke, S. M. (1983). Choice reaction time with a random foreperiod. Perception \& Psychophysics, 34, 195-208.

Hick, W. E. (1952). On the rate of gain of information. Quarterly Journal of Experimental Psychology, 4, 11-26.

HYMaN, R. (1953). Stimulus information as a determinant of reaction time. Journal of Experimental Psychology, 45, 188-196.

KARLIN, L. (1959). Reaction time as a function of foreperiod duration and variability. Journal of Experimental Psychology, 58, 185-191.

KLEMMER, E. T. (1956). Time uncertainty in simple reaction time. Journal of Experimental Psychology, 51, 179-184.

KLEMMER, E. T. (1957). Simple reaction time as a function of time uncertainty. Journal of Experimental Psychology, 54, 195-200.

MCLEOD, P. (1978). Does probe RT measure central processing demand? Quarterly Journal of Experimental Psychology, 30, 83-89.

NÄ̈TÄEN, R. (1971). Non-aging fore-periods and simple reaction time. Acta Psychologica, 35, 316-327.

Nickerson, R. S. (1967). Expectancy, waiting time and the psychological refractory period. Acta Psychologica, 27, 23-34.

Nickerson, R. S., \& Burnham, D. W. (1969). Response times with nonaging foreperiods. Journal of Experimental Psychology, 79, 452-457.

Posner, M. I. , KeEle, S. W. (1969). Attentional demands of movement. In Proceedings of the 16th Congress of Applied Psychology. Amsterdam: Swets and Zeittinger.

Salmoni, A. W., Sullivan, S. J., \& Starkes, J. L. (1976). The attention demands of movements: A critique of the probe technique. Journal of Motor Behavior, 8, 161-169.

WELFORD, A. T. (1952). The "psychological refractory period" and timing of high-speed performance-A review and a theory. British Journal of Psychology, 43, 2-19.

\section{NOTE}

1. It should be pointed out that there are situations in which the use of blocked ISIs is preferable. This would be the case where long ISIs are of interest and the investigator wishes to avoid effects due to the difficulty of maintaining preparation. Of course, the problem of timekeep- ing error is introduced. It should also be conceded that mental set may not remain constant with nonaging intervals, even over the brief ISIs of interest in most double-stimulation experiments. Fortunately, the method of nonaging intervals can be tested for the constancy of mental set with single-stimulation experiments. Moreover, the method is open to modifications so that the desired constancy may finally be obtained.

\section{APPENDIX}

Method for Generating Nonaging Waiting Intervals

The probability that a waiting interval will be longer than $T$ can be determined by integrating the probability density. The result is given below:

$$
P=\mathrm{e}^{-T / w}
$$

This expression converts time intervals that occur with an exponential probability distribution to probabilities that occur with a uniform probability distribution. The inverse of this function would take probabilities and generate the desired waiting intervals

$$
T=-W \ln (P)
$$

The RND function in the Basic programming language selects numbers at random from 0 to 1 with a uniform probability density. These numbers can be used to generate the nonaging waiting intervals using the following Basic statement:

$$
T=-W^{*} \operatorname{LOG}(\mathrm{RND})
$$

The following BASIC program will generate nonaging waiting intervals:

100 REM PROGRAM TO GENERATE WAITING
INTERVALS
110 REM
120 REM
130 INPUT "How many intervals would you like"; N
140 INPUT "What is the mean waiting interval"; W
$150 \quad$ FOR I = 1 TO N
$160 \quad$ T $=-W * L O G(R N D)$
$170 \quad$ PRINT T
$180 \quad$ NEXT I
$190 \quad$ END

(Manuscript received March 3, 1986; revision accepted for publication May 1, 1986.) 